\author{
Marquette University \\ e-Publications@Marquette
}

$10-2013$

\title{
Industrial Symbiosis: Corn Ethanol Fermentation, Hydrothermal Carbonization, and Anaerobic Digestion
}

\author{
Patrick J. McNamara \\ Marquette University, patrick.mcnamara@marquette.edu \\ Lindsey R. Jader \\ University of Minnesota \\ Frederick J. Schendel \\ University of Minnesota \\ Nicholas J. Hahn \\ University of Minnesota \\ Brandon M. Wood \\ University of Minnesota
}

See next page for additional authors

Follow this and additional works at: https://epublications.marquette.edu/civengin_fac

Part of the Civil and Environmental Engineering Commons

\section{Recommended Citation}

McNamara, Patrick J.; Jader, Lindsey R.; Schendel, Frederick J.; Hahn, Nicholas J.; Wood, Brandon M.; Valentas, Kenneth J.; Novak, Paige M.; and Heilmann, Steven J., "Industrial Symbiosis: Corn Ethanol Fermentation, Hydrothermal Carbonization, and Anaerobic Digestion" (2013). Civil and Environmental Engineering Faculty Research and Publications. 7.

https://epublications.marquette.edu/civengin_fac/7 


\section{Authors}

Patrick J. McNamara, Lindsey R. Jader, Frederick J. Schendel, Nicholas J. Hahn, Brandon M. Wood, Kenneth J. Valentas, Paige M. Novak, and Steven J. Heilmann 
Marquette University

e-Publications@Marquette

\title{
Civil and Environmental Engineering Faculty Research and Publications/College of Engineering
}

This paper is NOT THE PUBLISHED VERSION; but the author's final, peer-reviewed manuscript. The published version may be accessed by following the link in the citation below.

Biotechnology and Bioengineering, Vol. 110, No. 10 (April 08, 2013): 2624-2632. DOI. This article is (C) Wiley Periodicals and permission has been granted for this version to appear in ePublications@Marquette. Wiley Periodicals does not grant permission for this article to be further copied/distributed or hosted elsewhere without the express permission from Wiley Periodicals.

\section{Industrial Symbiosis: Corn Ethanol Fermentation, Hydrothermal Carbonization, And Anaerobic Digestion}

\author{
Brandon M. Wood
}

BioTechnology Institute, University of Minnesota, 140 Gortner Laboratory, 1479 Gortner Ave, St. Paul, Minnesota

Lindsey R. Jader

BioTechnology Institute, University of Minnesota, 140 Gortner Laboratory, 1479 Gortner Ave, St. Paul, Minnesota

Frederick J. Schendel

BioTechnology Institute, University of Minnesota, 140 Gortner Laboratory, 1479 Gortner Ave, St. Paul, Minnesota

Nicholas J. Hahn

BioTechnology Institute, University of Minnesota, 140 Gortner Laboratory, 1479 Gortner Ave, St. Paul, Minnesota

Kenneth J. Valentas 
BioTechnology Institute, University of Minnesota, 140 Gortner Laboratory, 1479 Gortner Ave, St. Paul, Minnesota

\section{Patrick J. McNamara}

Department of Civil, Construction and Environmental Engineering, Marquette University, Milwaukee, Wisconsin

\section{Paige M. Novak}

BioTechnology Institute, University of Minnesota, 140 Gortner Laboratory, 1479 Gortner Ave, St. Paul, Minnesota, 55108-1041

Department of Civil Engineering, University of Minnesota, St. Paul, Minnesota

\section{Steven M. Heilmann}

BioTechnology Institute, University of Minnesota, 140 Gortner Laboratory, 1479 Gortner Ave, St. Paul, Minnesota

\section{ABSTRACT}

The production of dry-grind corn ethanol results in the generation of intermediate products, thin and whole stillage, which require energy-intensive downstream processing for conversion into commercial animal feed products. Hydrothermal carbonization of thin and whole stillage coupled with anaerobic digestion was investigated as alternative processing methods that could benefit the industry. By substantially eliminating evaporation of water, reductions in downstream energy consumption from $65 \%$ to $73 \%$ were achieved while generating hydrochar, fatty acids, treated process water, and biogas co-products providing new opportunities for the industry. Processing whole stillage in this manner produced the four co-products, eliminated centrifugation and evaporation, and substantially reduced drying. With thin stillage, all four co-products were again produced, as well as a high quality animal feed. Anaerobic digestion of the aqueous product stream from the hydrothermal carbonization of thin stillage reduced chemical oxygen demand (COD) by more than $90 \%$ and converted $83 \%$ of the initial COD to methane. Internal use of this biogas could entirely fuel the HTC process and reduce overall natural gas usage. Biotechnol. Bioeng. 2013;110: 2624-2632. (C) 2013 Wiley Periodicals, Inc.

\section{Introduction}

Corn ethanol production in the U.S. has risen steadily, reaching 13.9 billion gallons in 2011 and rapidly approaching the amount mandated by the Energy Independence and Security Act (15 billion gallons by 2015). Use of corn in the production of ethanol has been controversial for a number of reasons, including energy and water consumption. Substantial improvements, however, have been achieved with the dry-grind ethanol process, which represents more than $80 \%$ of total US production capacity

(http://www.afdc.energy.gov/fuels/ethanol_production.html). Currently, net energy ratios, that is energy output/energy input, of 1.61-1.64 have been reported (Liska et al., 2009), and water use has decreased to 3-4 gallons of water per gallon of ethanol produced (Aden, 2007). Nevertheless, further reductions in energy and water use may be possible through alternative downstream processing.

When fermentation has finished and ethanol has been removed by distillation, the residue material is known as whole stillage (WS). WS is centrifuged to generate thin stillage (TS) as the centrate and wet distillers grains (WDG) as the centrifugate. TS has a high moisture content (>90\%) and only a portion of it, 10-50\% (Liu and Rosentrater, 2012), can be recycled into fermentation as backset due to the buildup and subsequent toxicity of low molecular weight organic compounds, inorganic salts, and solids (Alkan-Ozkaynak and Karthikeyan, 2011; Jacques et al., 1999). The remainder of TS is evaporated to obtain condensed distillers solubles (CDS), which is generally recombined with WDS, dried to a moisture content of $<10 \%$, and sold as dried distillers grains with 
solubles (DDGS) - a shelf-stable animal feed product that contributes to the economic viability of the industry. Energy intensive evaporation and drying of these intermediate products has been estimated to account for 40$45 \%$ of the thermal energy and $30-40 \%$ of the electrical energy required in the dry grind ethanol production process (Meredith, 2003).

Hydrothermal carbonization (HTC) is a thermochemical process that is especially well-suited for high moisture content biomass materials. Biomass is heated in water in a confined system at subcritical temperatures of generally $<250^{\circ} \mathrm{C}$. Two products are created that are separated by filtration: a hydrochar and an aqueous filtrate containing dissolved products. The vast majority of water is removed from the system by filtration and not by high energy evaporation; therefore, net energy output is generally positive. Previous work (Heilmann et al., 2011a) examined HTC of DDGS and generated hydrochars having high fuel value and other uses, as well as nutrient-rich aqueous product streams. Carbohydrates and proteins were shown to be involved in the chemical formation of the hydrochar, while lipids were hydrolyzed to fatty acids that sorbed onto the hydrochar. These fatty acids could be readily extracted from the hydrochar for subsequent use (Heilmann et al., 2011b). Despite these previous results, a lack of predictability exists in HTC reactions due to the complexity of substrates and chemistry. This makes extrapolation to other substrates, even seemingly analogous ones, difficult.

Anaerobic digestion (AD) could improve the overall energetics of ethanol manufacturing by replacing a portion of natural gas with biogas and reducing water consumption by allowing recycle of digestate water back into fermentation. Efficient digestion of TS has been achieved by others (Agler et al., 2008; Andalib et al., 2012; Schaefer and Sung, 2008), with a hydraulic retention time as brief as 3.5 days (Andalib et al., 2012), and biogas created in the process could provide a $43-59 \%$ reduction of the natural gas requirement. It has also been suggested that the effluent from digested TS could be employed as backset without disrupting ethanol production (Alkan-Ozkaynak and Karthikeyan, 2011). Because TS contains diverse nutrients and minerals, only trace cobalt supplementation is likely to be required for long-term digestion (Agler et al., 2008). Despite potential benefits, anaerobic digestion of stillage intermediates has failed to gain traction in the industry.

Integration of HTC and AD could allow for the generation of new co-products, hydrochar, and fatty acids from HTC and biogas and decreased water usage from AD of the hydrochar filtrate stream. Even so, as determined in investigations of thermal hydrolysis (which is a milder form of HTC employed by the waste processing industry) of wastewater sludge (Bougrier et al., 2008), temperatures above $190^{\circ} \mathrm{C}$ decreased the subsequent digestibility due to formation of Maillard compounds. The extent of this decrease in biodegradability is largely unknown with thermal hydrolysis temperatures above $210^{\circ} \mathrm{C}$, especially for substrates other than wastewater sludge.

Additionally, when wastewater sludge undergoes thermal hydrolysis, the entire stream is subjected to digestion and any hydrochar formed is typically not removed. Thus, it remains unclear what the effects of generating and removing the hydrochar will have on digestion.

The overall objective of this research was to determine if HTC and AD could be effectively integrated into the dry-grind corn ethanol process to provide hydrochar, fatty acids, biogas, and treated process water. Two separate scenarios are proposed (Fig. 1B and 1C) compared to the conventional dry-grind process (Fig. 1A). The use of WS for an HTC feed stream has advantages of completely eliminating the need for centrifugation and evaporation; no animal feed product would remain, however. Compared to conventional processes, the use of TS as an HTC feed stream eliminates evaporation and minimizes drying, while continuing to produce an animal feed product (DDG). Because the current market for animal feed is strong, more emphasis was placed on the utilization of TS. For this study, the specific objectives included: (1) evaluate HTC and AD as alternative and potentially more energy efficient downstream processing operations for stillage intermediates, (2) determine if water consumption can be reduced by recycling more process water following HTC or AD, and (3) generate additional co-product options. 


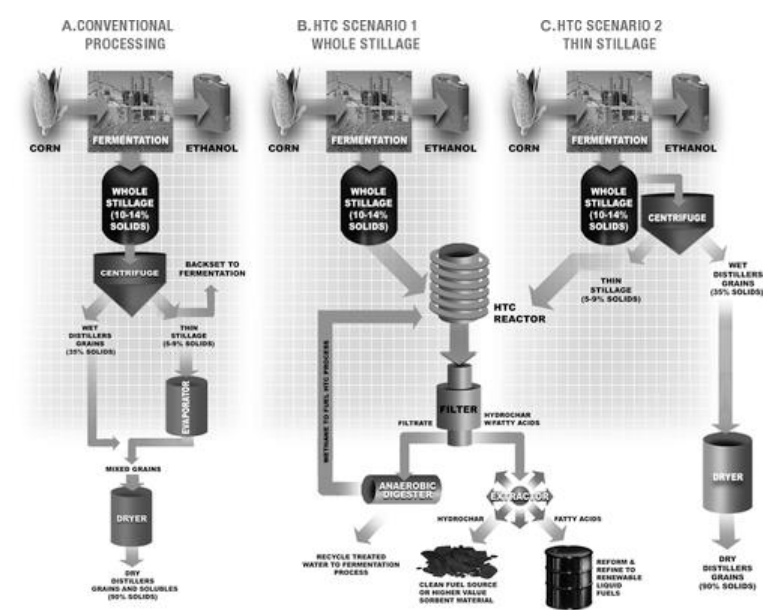

Figure 1 A: Simplified schematic of a conventional dry-grind corn ethanol plant. B: Whole stillage scenario wherein centrifugation, evaporation, and a majority of drying is eliminated. C: Thin Stillage scenario wherein evaporation is eliminated and dry distillers grain can continue to be utilized as an animal feed.

\section{Materials and Methods}

\section{Hydrothermal Carbonization}

Procedures for HTC of both WS and TS were the same, with the exception of cooling temperature. Samples of authentic TS and WS were obtained from Al-Corn Clean Fuels, Inc. (Claremont, MN). All reactions were conducted in a $450 \mathrm{~mL}$ stirred stainless steel reactor available from Parr Instruments, Inc. (Moline, IL). Heating was applied using an inductive heating system available from LC Miller, Co. (Monterey Park, CA). TS or WS were poured into the reactor, stirred at $88 \mathrm{rpm}$, and heated to the specified temperature for the defined time. The pressure in the reactor was autogenous, and the apparatus was cooled using a fan. When the unit had cooled to at least $35^{\circ} \mathrm{C}$ for TS or $45^{\circ} \mathrm{C}$ for WS, the reactor was disassembled, the contents were filtered, and the hydrochar was washed thoroughly with distilled water. The sterile filtrate was stored at $4^{\circ} \mathrm{C}$, and moist hydrochar was freeze-dried to obtain dry hydrochar. Extraction of fatty acids from the hydrochar was accomplished using methyl $t$-butyl ether (MTBE). The extracted hydrochar was dried overnight at $40^{\circ} \mathrm{C}$ followed by additional drying at $<1$ Torr. MTBE was removed from the extract using a rotary evaporator.

\section{Design of Experiments}

Reaction conditions examined with TS were temperatures from 200 to $240^{\circ} \mathrm{C}$, times from 0.5 to $2.0 \mathrm{~h}$, and percent solids values from 5.3 to 9.1 (Table I). WS experiments were conducted with temperatures from 200 to $230^{\circ} \mathrm{C}$, times from 0.5 to $2.0 \mathrm{~h}$, and percent solids values from 10.0 to 14.0 (Table II). The three percent solids levels employed with TS were obtained by atmospheric distillation of water from the as-received TS (7.2\% solids) until a percent solids level of $9.1 \%$ was achieved. The lowest concentration ( $5.3 \%$ solids) was obtained by dilution of the as-received TS with distilled water. In the course of conducting experiments with WS and despite refrigerated storage, it was noted that percent solids values changed with time. Because the percent solids of the WS changed over time despite refrigeration, an additional sample of WS was freeze-dried, homogenized to a powder, and stored at $-20^{\circ} \mathrm{C}$ prior to use. This dry material was reconstituted to $10 \%, 12.0 \%$, and $14.0 \%$ solids by the addition of distilled water and homogenization with a Waring blender. 
Table I. Reaction conditions, elemental analysis, and yields of thin stillage and resulting extracted hydrochars

\begin{tabular}{|c|c|c|c|c|c|c|c|c|c|c|c|c|}
\hline $\begin{array}{l}\text { Process } \\
\text { conditions }\end{array}$ & & & $\begin{array}{l}\text { Elemental } \\
\text { analysisa }\end{array}$ & & & & & & Hydrochar & $\begin{array}{l}\text { Fatty } \\
\text { acid }\end{array}$ & HHV & $\begin{array}{l}\% \\
\text { Ashe }\end{array}$ \\
\hline Temp ( $\left.{ }^{\circ} \mathrm{C}\right)$ & $\begin{array}{l}\text { Time } \\
\text { (h) }\end{array}$ & $\begin{array}{l}\text { \% } \\
\text { Solids }\end{array}$ & $\% \mathrm{C}$ & $\% \mathrm{H}$ & $\% N$ & $\% 0$ & $\% \mathrm{~S}$ & $\% P$ & $\%$ Yieldb & $\%$ Yieldc & BTU/lbd & \\
\hline TS & - & - & 44.35 & 7.85 & 2.79 & 37.06 & 0.29 & 1.87 & - & - & 8,339 & 12.9 \\
\hline 200 & 0.5 & 5.3 & 60.45 & 6.83 & 9.26 & 22.79 & - & - & $4.15(5.7)$ & 46.91 & - & - \\
\hline 200 & 0.5 & 9.1 & 61.48 & 6.62 & 8.84 & 22.52 & - & - & $6.38(8.9)$ & 45.40 & - & - \\
\hline 200 & 2.0 & 5.3 & 66.11 & 6.68 & 7.03 & 19.33 & - & - & $6.04(9.0)$ & 66.09 & - & - \\
\hline 200 & 2.0 & 9.1 & 65.86 & 6.54 & 6.99 & 19.24 & - & - & $7.63(11.3)$ & 42.97 & - & - \\
\hline 220 & 1.25 & 7.2 & 65.28 & 6.49 & 6.40 & - & - & - & $6.08(9.0)$ & 59.09 & - & - \\
\hline 220 & 1.25 & 7.2 & 62.50 & 6.22 & 6.27 & 17.43 & 0.39 & 1.21 & $6.09(8.6)$ & 47.19 & $12,647(14,477)$ & 5.23 \\
\hline 220 & 1.25 & 7.2 & 63.98 & 6.34 & 6.31 & - & - & - & $6.08(8.8)$ & 51.30 & - & - \\
\hline 240 & 0.5 & 5.3 & 59.68 & 5.78 & 6.19 & 16.16 & - & - & $4.38(5.9)$ & 43.78 & - & - \\
\hline 240 & 0.5 & 9.1 & 59.60 & 5.80 & 6.25 & 15.32 & - & - & $6.68(9.0)$ & 51.15 & - & - \\
\hline 240 & 2.0 & 5.3 & 48.66 & 4.98 & 4.10 & 13.07 & - & - & $4.14(4.5)$ & 32.96 & - & - \\
\hline 240 & 2.0 & 9.1 & 51.45 & 5.22 & 4.55 & 12.12 & - & - & $7.10(8.2)$ & 63.57 & - & - \\
\hline
\end{tabular}

${ }^{a} \%$ based on dry weights of starting thin stillage and extracted hydrochars.

${ }^{b}$ Yield based on dry weights. Values in parentheses are $\%$ of total carbon recovered in extracted hydrochar.

${ }^{c}$ Yield based on thin stillage dry solids with $17.52 \%$ fatty acids and an extract concentration of $84 \%$ fatty acids.

${ }^{d} \mathrm{HHV}$ of unextracted hydrochar in parentheses.

${ }^{e}$ Thin stillage value from literature (Kim et al., 2008).

Table II. Reaction conditions, elemental analysis, and yields of whole stillage and resulting extracted hydrochars

\begin{tabular}{|c|c|c|c|c|c|c|c|c|c|c|c|}
\hline Process conditions & & & Elemental analysisa & & & & & Hydrochar \% & Fatty acid \% & HHV & \% Ashe \\
\hline Temp $\left({ }^{\circ} \mathrm{C}\right)$ & Time (h) & \% Solids & $\% \mathrm{C}$ & $\% \mathrm{H}$ & $\% \mathbf{N}$ & $\% S$ & $\% \mathrm{P}$ & Yieldb & Yieldc & BTU/Ibd & \\
\hline WS & - & - & 45.99 & 7.58 & 4.03 & 0.34 & 1.11 & - & - & 8738 & 5.0 \\
\hline 200 & 0.5 & 10 & 59.45 & 6.80 & 7.19 & - & - & $18.45(23.8)$ & 75.97 & - & - \\
\hline 200 & 0.5 & 14 & 59.21 & 6.69 & 6.87 & - & - & $20.78(26.7)$ & 81.58 & - & - \\
\hline 200 & 2.0 & 10 & 63.10 & 6.52 & 5.50 & - & - & $18.07(24.8)$ & 93.38 & - & - \\
\hline 200 & 2.0 & 14 & 63.15 & 6.55 & 5.69 & - & - & 19.65 (26.9) & 92.61 & - & - \\
\hline 215 & 1.25 & 12 & 64.85 & 6.52 & 5.72 & - & - & $17.55(24.7)$ & 91.23 & - & - \\
\hline 215 & 1.25 & 12 & 65.54 & 6.62 & 5.90 & - & - & $17.65(25.2)$ & 90.75 & - & - \\
\hline 215 & 1.25 & 12 & 65.01 & 6.63 & 5.52 & 0.47 & 0.18 & $17.72(25.0)$ & 90.16 & 11819(13889) & 0.83 \\
\hline 215 & 1.25 & 12 & 65.28 & 6.73 & 5.48 & - & - & $17.79(25.2)$ & 89.27 & - & - \\
\hline
\end{tabular}




\begin{tabular}{|l|l|l|l|l|l|l|l|l|l|l|l|}
\hline 230 & 0.5 & 10 & 64.51 & 6.51 & 5.96 & - & - & $16.00(22.4)$ & 82.35 & - & - \\
\hline 230 & 0.5 & 14 & 64.88 & 6.54 & 6.07 & - & - & $17.33(24.4)$ & 88.71 & - & - \\
\hline 230 & 2.0 & 10 & 66.66 & 6.64 & 5.60 & - & - & $15.49(22.4)$ & 97.60 & - & - \\
\hline 230 & 2.0 & 14 & 65.48 & 6.53 & 5.61 & - & - & $16.68(23.7)$ & 101.79 & - & - \\
\hline
\end{tabular}

a \% based on dry weights of starting whole stillage and extracted hydrochars.

${ }^{b}$ Yield based on dry weights. Values in parentheses are $\%$ of total carbon recovered in extracted hydrochar.

${ }^{c}$ Yield based on whole stillage dry solids with $12.84 \%$ fatty acids and an extract concentration of $84 \%$ fatty acids.

${ }^{d} \mathrm{HHV}$ of unextracted hydrochar in parentheses.

${ }^{e}$ Whole stillage value from literature (Kim et al., 2008). 
Hydrochar and Fatty Acid Analysis

Elemental analyses, heats of combustion, and ash contents were determined by Huffman Laboratories, Inc. (Golden, CO). BET surface areas of hydrochars were determined by the Chemical Engineering Department, University of Minnesota. HPLC analyses of filtrates were conducted using an Agilent $1200 \mathrm{HPLC}$ equipped with an Aminex-87H column $(300 \mathrm{~mm} \times 7.8 \mathrm{~mm})$ at $50^{\circ} \mathrm{C}$ using an isocratic program of $5 \mathrm{mM}$ sulfuric acid and a flow rate of $0.5 \mathrm{~mL} / \mathrm{min}$, with $1 \%$ sodium propionate as an internal standard. Total fat, fatty acid profiles, and percent triglyceride values were determined (House et al., 1994) by Medallion Labs Inc. (Minneapolis, MN).

\section{Substrate and Inoculum Characterization}

Prior to digestion experiments, the total solids for the inoculum was determined gravimetrically at $103^{\circ} \mathrm{C}$, while total solids for TS and HTC filtrates were determined via freeze-drying due to their low initial pH (Angelidaki et al., 2009). Volatile solids levels were determined gravimetrically at $550^{\circ} \mathrm{C}$. Total chemical oxygen demand (TCOD) values were determined using Hach COD Test Kits (ultra-high range, Hach Co., Loveland, CO) according to a literature procedure of Jirka and Carter (1975). Samples were not blended prior to COD testing due to foaming. $\mathrm{pH}$ was measured before and after batch experiments using a Thermo Orion $330 \mathrm{pH}$ meter. Alkalinity of substrates was determined by the Soil Sciences Analytical Laboratory at the University of Minnesota.

\section{Anaerobic Digestion Experiments}

Biochemical Methane Potential (BMP) assays were used as a test of biodegradability of the HTC filtrate streams and the initial TS according to a literature procedure (Owen et al., 1979) with the exception that no additional nutrients or buffers were added. Three concentrations, $35 \%, 65 \%$, and $100 \%$, of untreated TS and HTC filtrate substrates were examined in triplicate. Triplicate controls consisted of inoculum only or $100 \%$ HTC filtrate without an inoculum added. Inoculum was removed from source reactors (description in Supplementary S.1) anaerobically and allowed to degas for 2 days prior to use. Serum bottles (160 mL) were filled with $21 \mathrm{~mL}$ of inoculum, with the exception of the negative control, and fed $9 \mathrm{~mL}$ of substrate. Millipore water was utilized in lieu of inoculum or the substrate in the two controls. Immediately after inoculation, bottles were purged with $\mathrm{N}_{2}$ for $2 \mathrm{~min}$, sealed with butyl rubber stoppers, and allowed to equilibrate at the incubation temperature $\left(37^{\circ} \mathrm{C}\right)$ for $1 \mathrm{~h}$ before being degassed to initiate the experiment. The BMP assays were performed at $37^{\circ} \mathrm{C}$ while being mechanically shaken at $90 \mathrm{rpm}$. Biogas production and methane production were measured once each day for the first 8 days and another seven times in the following 21 days (total experimental period of 30 days). Biogas production was measured by the volumetric displacement of the barrel of a wetted glass syringe. Biogas was subsequently exhausted from the assays to re-establish atmospheric pressure. The methane content of the biogas was measured via GC (see Supplementary S.2) immediately after establishing atmospheric pressure in the bottles. After 30 days the bottles were opened and $\mathrm{pH}$, total solids, volatile solids, and TCOD were measured. Details of the BMP analysis are given in Supplementary S.3.

\section{Results and Discussion}

\section{Hydrothermal Carbonization (HTC) Experiments}

Hydrothermal carbonization and subsequent filtration of TS and WS resulted in the production of solid carbonized hydrochars, sorbed fatty acids, and filtrate streams (Tables I and II). Carbon contents of the TS and WS increased from $44.3 \%$ and $46 \%$ to center point averages of $63.9 \%$ and $65.15 \%$, respectively. Unextracted hydrochars had high heats of combustion and lost ca. 13-15\% on extraction, similar to what has been observed in the literature with DDGS as the HTC substrate (Heilmann et al., 2011a). Ash contents of hydrochars were reduced compared to starting stillages, and the ash of TS hydrochar was about six times that of the WS hydrochar. Increased ash content of the TS hydrochar probably derives from TS having essentially all of the salts in the system being present either as solutes or colloidal particles, and any multivalent metal cations, for 
example, $\mathrm{Fe}, \mathrm{Ca}, \mathrm{Mg}$, and $\mathrm{Al}$, present along with corresponding anions like phosphate form insoluble metal salts that precipitate and collect within the hydrochar. As with HTC of microalgae (Heilmann et al., 2010) and DDGS (Heilmann et al., 2011a), phosphorus ( $>95 \%$ for TS and $>97 \%$ WS) and nitrogen ( $>85 \%$ for TS and $>75 \%$ for WS) were primarily located in the filtrate streams.

For the design of experiments series, the orthogonal design of these experiments allowed for a linear regression analysis that identified the significance of time, temperature, and concentration (percent solids) input variables on specific outputs. Equations with an $R^{2}$ of at least 0.95 are shown in Table III (full statistical analysis Supplementary S.4). TS hydrochar yields decreased with temperature and temperature $\times$ time interaction, but increased with time and concentration. Similarly, WS hydrochar yield decreased with temperature and temperature $\times$ concentration interaction, and increased with concentration. WS hydrochar yield, however, decreased with time. With both WS and TS, increased yields were obtained at higher solids. Although this input could be controlled to some extent for WS by distillation conditions and for TS by centrifuge conditions, it is impractical for manufacturers to attempt to modify solids substantially. The equation for percent nitrogen in the TS hydrochar indicated that percent solids had no significant effect, while temperature and time had large negative effects. WS fatty acid yields were maximized by increasing temperature and time. Overall, lower temperatures and retention times are favored for continuous processing because they reduce the size and the pressure rating of the equipment required.

Table III. Linear regression equations having $R^{2}$ values $>0.95$ that were obtained from designed stillage experiments of Tables I and II

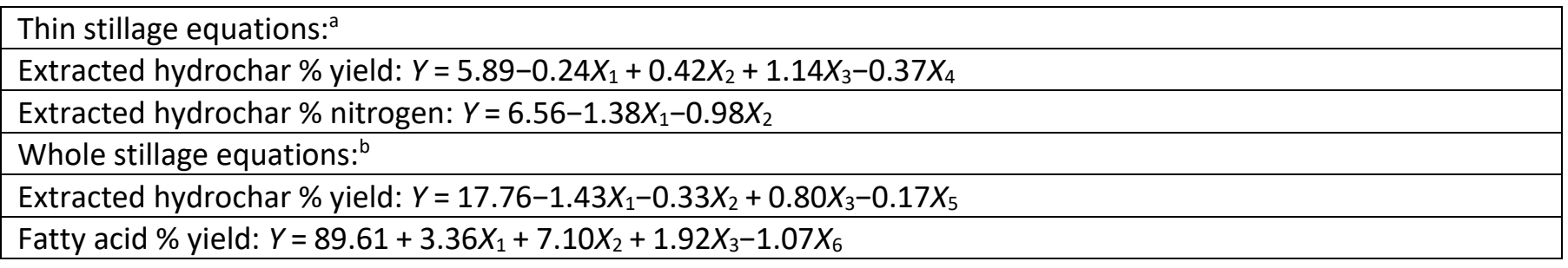

$X_{1}=$ temperature, $X_{2}=$ time, $X_{3}=$ solids, $X_{4}=$ temperature $\times$ time, $X_{5}=$ temperature $\times$ solids, $X_{6}=$ time $\times$ solids.

${ }^{\mathrm{a}, \mathrm{b}} \mathrm{All}$ variables have dimensionless units between -1 and +1 corresponding to the low and high experimental conditions.

Triglycerides present in TS and WS were hydrolyzed and sorbed onto hydrochars as fatty acids (yields in Tables I and II). Total gravimetric fat values, percent triglyceride, and fatty acid contents measured by GC of freeze-dried TS were $19.41 \%, 18.32 \%$, and $17.52 \%$ and for WS $14.81 \%, 13.42 \%$, and $12.84 \%$. Fatty acid components for both stillages were essentially the same, with palmitic (16:0), stearic (18:0), oleic (18:1), linoleic (18:2) and linolenic (18:3) acids comprising 14.5\%, 1.9\%, 25.3\%, 55.0\%, and 1.4\% respectively, for a total of 98.1\%. The weight-average molecular weight used for mass computations of fatty acids present in extracts was $276 \mathrm{~g} / \mathrm{mol}$ (Heilmann et al., 2011b). HTC treatment had little effect on fatty acids in the system, as the fatty acid profile of the extract from the center point WS hydrochar was essentially unchanged from the profile of starting WS and contained the following fatty acids: $16: 0,13.9 \% ; 18: 0,2.0 \% ; 18: 1,25.6 \% ; 18: 2,51.5 \%$; and 18:3, 1.2\% (97.0\% of the fatty acids present).

\section{Hydrochar and HTC Mechanism}

The mechanism of carbonization with TS was explored via construction of a Van Krevelen diagram (Van Krevelen, 1950) in which changes in $\mathrm{H} / \mathrm{C}$ and $\mathrm{O} / \mathrm{C}$ ratios are plotted for starting biomass and coalified products. With this technique, a slope of 2 indicates a dehydration process, while slopes $<2$ provide evidence for decarboxylation. When the $\mathrm{H} / \mathrm{C}$ versus $\mathrm{O} / \mathrm{C}$ ratios were plotted for starting TS and TS derived hydrochars 
obtained at the various reaction conditions (data in Table I), all of the hydrochars were located within a relatively tight cluster and the slope of the line $\left(R^{2}=0.98\right)$ between the starting TS and the center of the cluster was 2.09, indicating that dehydration was the principal carbonization process occurring under the reaction conditions. Interestingly, decarboxylation was the principal mechanistic pathway identified in a related study of HTC of anaerobically digested maize silage (Mumme et al., 2011). A slope of 0.90 supported the authors' conclusion that substantial decarboxylation had occurred with that substrate during carbonization.

Hydrochars having significantly decreased $\mathrm{O} / \mathrm{C}$ ratios relative to starting biomass can be utilized as carbonneutral fuels having coal-like heating values. Very low extracted yields and relatively high nitrogen contents due to proteins in the stillages (Tables I and II), however, suggested that other applications need to be explored.

As with other hydrochars surface areas are quite low ( $2.2 \mathrm{~m}^{2} / \mathrm{g}$ for center point TS), but functional groups such as carboxylic acid groups have been determined to be more prevalent on surfaces of hydrochars than on biochars (Chen et al., 2011). It may be that a significant quantity of the nitrogen content may be in the form of basic amine groups also present on the surface of hydrochars and thereby more accessible to solutes. The presence of both acidic and basic functional groups could provide for mixed bed ion exchange behaviors and unexpected utility for these materials.

Additionally, it has been determined that post-thermal treatments can increase surface areas and carbonization levels considerably, thereby providing the potential for stillage hydrochars to be converted into significantly higher value co-products. For example, recent reports have disclosed a transformation of hydrochars into supercapacitors for electrode materials (Falco et al., 2013; Wei et al., 2011) and carbon dioxide sorbents (Sevilla et al., 2012).

\section{Fatty Acids and Animal Feed Products}

HTC processing did not appreciably alter the composition of fatty acids present in either WS or TS; notably, even the polyunsaturated acid, linoleic acid, underwent only a $1 \%$ change in concentration. Similar low conversions of fatty acids under HTC conditions have been reported (Wilson and Novak, 2009). Fatty acid yields, however, were markedly different with the two stillages. TS gave lower yields of fatty acids compared to WS, which was largely attributed to the relatively small quantities of hydrochar formed from the TS. Because hydrochars sorb the fatty acids, actual masses, and extracted yields of only $4.2-7.1 \%$ for the TS hydrochars compared to $15.5-20.8 \%$ with WS were obvious factors. These were apparently not the only factors, however, as reproducibility of fatty acid yields in the replicate TS center point experiments was poor, that is, $47-59 \%$, despite having the same masses of sorbing hydrochars produced in all three experiments. This suggested that the reaction workup procedure may have been a factor, and variations in the cool-down procedure, for example, time and final temperature achieved, may have played roles in the fatty acid yield. These factors were investigated and it was determined that a final product mixture temperature of $45^{\circ} \mathrm{C}$ provided an optimum fatty acid yield of $68 \%$ for TS center point conditions. This modification was applied in the workup of the WS materials in Table II, resulting in essentially the same extracted fatty acid yield for all four replicate center point experiments. A possible explanation of this phenomenon was that a ripening process may have occurred upon hydrochar cooling, involving both the sorption and desorption of fatty acids from the hydrochars. At temperatures below $45^{\circ} \mathrm{C}$, possible formation of relatively stable micelles of fatty acids in the aqueous suspending medium may have competed with the collection of fatty acids on the hydrochars, causing a decrease in fatty acid yields.

Corn oil from TS or CDS has become a valuable co-product in the dry grind ethanol industry. One of the more prevalent technologies to remove the oil from CDS is centrifugation, with typical oil yields of ca. $30 \%$ (private communication from Randall Doyal of Al-Corn Clean Fuels, Inc.). By contrast, fatty acids extracted from center point TS and WS hydrochars were obtained in $68 \%$ and $90 \%$ yields, respectively. These fatty acids can be 
converted directly into biodiesel or other liquid transportation fuels, providing yet another benefit of the HTC process.

The practicality of either HTC scenario depends to a considerable extent on the animal feed market. With HTC of TS, an animal feed (dry distillers grains [DDG]), is produced that is equivalent to or may actually exceed DDGS in feed quality as a result of its higher protein and lower lipid content (Dahlen et al., 2011).

\section{HTC Process Water Backset}

Recycle of process water could occur employing the filtrate directly after HTC or after AD, but the choice of direct recycle versus digestion followed by recycle depends on a number of factors. Lactic acid, acetic acid, and glycerol present in HTC filtrate streams may negatively impact both the growth of yeast and the fermentation process. Indeed, the growth of yeast in fermentation can be inhibited when lactic acid, acetic acid, and glycerol levels are present in excess of $0.80 \%, 0.05 \%$, and $1.0 \%$, respectively (Jacques et al., 1999). In our experiments, lactic acid concentrations were well below the $0.80 \%$ limit, ranging from $0.16 \%$ to $0.23 \%$ with WS and 0.18 to $0.32 \%$ with TS. Acetic acid levels, however, exceeded $0.05 \%$ in some cases, with the WS samples ranging from $0.07 \%$ to $1.0 \%$ and the TS samples ranging from $0.02 \%$ to $0.07 \%$. As anticipated, glycerol levels were high as a result of extensive hydrolysis of triacylglycerides, ranging from $0.84 \%$ to $1.03 \%$ with WS samples and $0.96-1.50 \%$ with TS samples. From this analysis there would seem to be little benefit in recycling HTC filtrates directly. After $A D$, however, it is likely that the filtrate will contain few if any of these compounds (Alkan-Ozkaynak and Karthikeyan, 2011), and the digestate may be effectively recycled. Whether Maillard or other inhibitory compounds and by-products formed during the HTC process may adversely affect AD requires further research.

\section{Batch Anaerobic Digestion}

Biochemical methane potential (BMP) assays established that $\mathrm{HTC}$ filtrate generated from $\mathrm{TS}$ at $220^{\circ} \mathrm{C}$ could readily be digested. Substrate and inoculum characterization determined that $\mathrm{HTC}$ processing reduced total solids and TCOD of TS by ca. $30 \%$ and $45 \%$, respectively, while maintaining a volatile solid to total solid ratio of 0.84 compared to 0.87 for TS (Table IV). Specific methane production, corrected to STP, from all the BMP assays is shown in Figure 2. Total inoculum methane production was low ( $18.5 \mathrm{~mL}$ at STP), which was subtracted from the values presented in Figure 2. Unaltered methane production data are given in Supplementary S.5. Initially, none of the treatments appeared to go through an acclimation or lag phase prior to methane production. From Day 7 to Day 12, however, there was a notable lag in methane production in the $100 \%$ HTC treatment, with two of the three reactors producing methane at reduced rates shown through increased standard deviations (Fig. 2). All of the concentrations of either the TS or HTC filtrate treatments (35\%,65\%, and $100 \%$ ) produced essentially the same quantity of total methane per gram of initial COD, indicating that the undiluted substrates were not toxic. Furthermore, TS and the HTC filtrates, again at all concentrations, proved to be highly biodegradable, as evidenced by $>90 \%$ reductions in total COD over the incubation period (Table $\mathbf{V}$ ). In addition, $91 \%$ and $83 \%$ of the initial COD was converted into methane for the $100 \%$ TS and $100 \% \mathrm{HTC}$ filtrate samples, respectively (Fig. 3). Multiple comparisons using a studentized range $(\alpha=0.05)$ demonstrated that there were statistically significant differences between the HTC filtrates and the corresponding untreated TS samples with respect to the percent of initial COD converted to methane (Fig. 3).

Table IV. Initial characteristics of inoculum and substrates

\begin{tabular}{|l|l|l|l|l|}
\hline & Total solids (\% w/w) & Volatile solids (\% w/w) & $\mathbf{p H}$ & Alkalinity $\mathbf{~ m g ~} \mathrm{CaCO}_{\mathbf{3}} / \mathbf{L}$ \\
\hline Thin stillage & $5.72 \pm 0.003$ & $4.99 \pm 0.02$ & 4.71 & 0 \\
\hline HTC filtrate & $4.02 \pm 0.02$ & $3.36 \pm 0.01$ & 4.82 & 0 \\
\hline Inoculum & $3.47 \pm 0.02$ & $2.30 \pm 0.02$ & 8.16 & 9803.3 \\
\hline
\end{tabular}



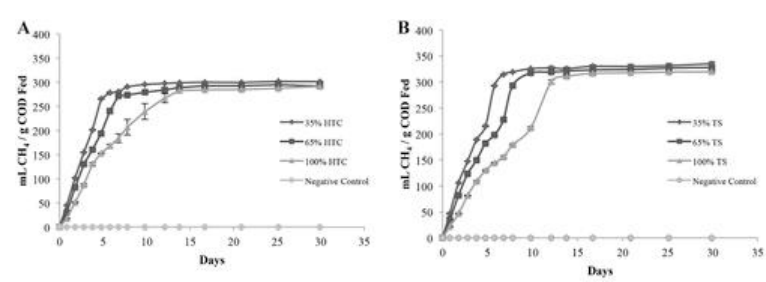

Figure 2 Specific methane production at STP of HTC filtrate generated at $220^{\circ} \mathrm{C}$ from TS (A) and untreated TS (B) from BMP assays. Background methane production from inoculum has been subtracted and error bars represent standard deviation.

Table V. Total chemical oxygen demand

\begin{tabular}{|l|l|l|l|l|}
\hline Treatment & Initial $(\mathbf{m g} / \mathbf{L})$ & Final S/I mixture (mg/L)a & Final (mg/L)b & \% Removal \\
\hline $35 \%$ HTCc & $17,547 \pm 970$ & $21,700 \pm 819$ & $1,600 \pm 927$ & $91 \pm 5$ \\
\hline $65 \%$ HTCc & $32,587 \pm 970$ & $22,600 \pm 781$ & $2,500 \pm 894$ & $92 \pm 3$ \\
\hline $100 \%$ HTC & $50,133 \pm 970$ & $24,467 \pm 551$ & $4,367 \pm 702$ & $91 \pm 1$ \\
\hline $35 \%$ TSc & $31,181 \pm 484$ & $21,400 \pm 557$ & $1,300 \pm 707$ & $96 \pm 2$ \\
\hline $65 \%$ TSc & $57,908 \pm 484$ & $22,033 \pm 874$ & $1,933 \pm 976$ & $97 \pm 2$ \\
\hline $100 \%$ TS & $89,089 \pm 484$ & $24,733 \pm 1930$ & $4,633 \pm 1,978$ & $95 \pm 2$ \\
\hline Negative controlc & $15,040 \pm 970$ & $13,167 \pm 115$ & N/A & $12 \pm 6$ \\
\hline Inoculum controlc & $24,795 \pm 342$ & $20,100 \pm 436$ & N/A & $19 \pm 2$ \\
\hline
\end{tabular}

${ }^{a}$ Final COD values measured from substrate/inoculum (S/I) mixture.

${ }^{b}$ Values calculated by subtracting inoculum control from $\mathrm{S} / \mathrm{I}$ mixture.

${ }^{c}$ Initial COD values calculated using dilution factor.

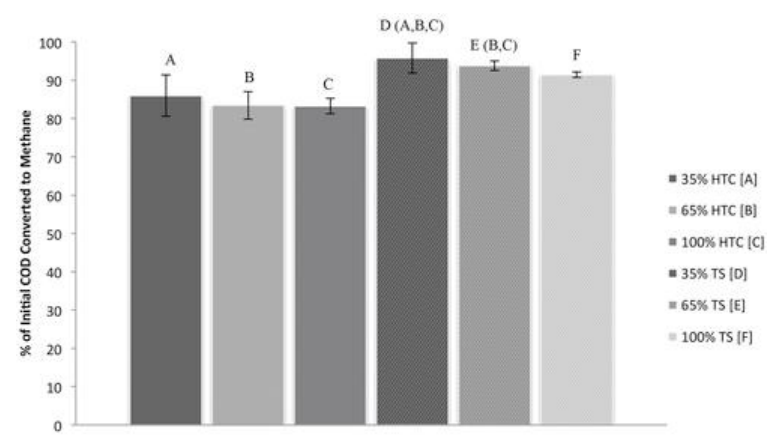

Figure 3 Percent of initial COD converted to methane. Methane to COD conversion was calculated using measured total methane production excluding background methane from inoculum and the theoretical value $0.35 \mathrm{~L} \mathrm{CH}_{4}=1 \mathrm{~g}$ COD. Corresponding letters in parentheses represent significant differences by studentized range $(\alpha=0.05)$. Error bars represent standard deviation.

Interestingly, initial rate constants of methane production were lowered by $\mathrm{HTC}$ processing at $220^{\circ} \mathrm{C}$. Over the initial linear phase (5 days) of methane production, HTC filtrate had an initial rate constant of $38.00 \mathrm{~mL}$ $\mathrm{CH}_{4}$ gVS $^{-1}$ day ${ }^{-1}$ while TS, when compared on an equivalent COD basis, provided an initial rate of $44.66 \mathrm{~mL}$ $\mathrm{CH}_{4} \mathrm{gVS}^{-1}$ day $^{-1}$ at STP (TS initial rate constant was calculated by using a polynomial fit model Supplementary S.3). Apparently, HTC treatment generated organic compounds that were more difficult to degrade relative to initial compounds present in TS. TS was probably more digestible without HTC pretreatment because it had undergone enzymatic hydrolysis prior to fermentation and contained acetic acid which provided acetate, the primary carbon and energy source for methanogenesis. Other pretreatment methods such as sonication offered little or no benefit to TS digestion (Schaefer and Sung, 2008). In an effort to improve the rate of methane production, 
thermophilic digestion should be investigated since metabolic rates of methanogens can double (Khanal, 2008), and in that instance there would be no need to heat the influent HTC stream.

\section{Energy Analysis}

Energy analysis was conducted by comparing the requirements for HTC versus those of conventional downstream processing to generate a shelf-stable co-product, defined as $90 \%$ solids. Conventional energy input values were obtained from a literature report (Rausch and Belyea, 2006), whereas HTC energy input values were computed from an enthalpy balance. A detailed set of assumptions and computations are available in Supplementary S.6. The results showed that HTC processing would reduce energy consumption by $73 \%$ for TS and $65 \%$ for WS compared to conventional downstream processing operations. For the TS scenario, the preliminary evaluation of methane production rates indicated that AD of HTC filtrates could provide all of the energy needed to fuel the HTC process (Supplementary S.7).

\section{Conclusion}

HTC and subsequent AD of stillage intermediates can be successfully combined to generate biogas, treated process water, hydrochar, and fatty acids. The first objective of this study was to improve the overall energy balance of dry-grind corn ethanol production by modifying downstream processing of stillage intermediates. By eliminating the need for evaporation and some of the drying, operational energy requirements were considerably reduced and sufficient on-site biogas could be produced for the HTC process and other natural gas operations. Reducing water consumption was the second objective, and HPLC analysis indicated that HTC filtrates do require treatment in order to increase backset. AD of the filtrate consumed $>90 \%$ of the TCOD and converted more than $80 \%$ of that initial COD to methane. A final objective was to develop options with respect to new or improved co-products. TS fatty acid yields of $68 \%$ are a marked improvement compared to the current industry average of $30 \%$ triglycerides. With TS, the HTC process would also provide an animal feed product higher in protein and lower in fat than DDGS. Hydrochars were shown to have good fuel value, but other higher value applications need to be developed due to low extracted hydrochar yields and relatively high nitrogen contents. Significant opportunities to bring greater value to the industry may accrue from characteristic high surface functionalities of hydrochars and, especially through post-thermal treatments. In closing, although a more detailed techno-economic analysis is necessary to determine the economic viability of the proposed model, this process appears promising for increasing the sustainability of the dry-grind corn ethanol industry.

\section{Acknowledgments}

The authors would like to thank the Minnesota Corn Growers Association. This work was supported, in part, by the farm families of Minnesota and their corn check-off investment. Financial support was also received from the College of Biological Sciences, the Biotechnology Institute, and the Institute for Renewable Energy and the Environment of the University of Minnesota. Much thanks to Mr. Randall Doyal of Al-Corn Clean Fuels, Inc. of Claremont, MN for authentic samples and information about the industry. Mr. Timothy Montgomery and Mr. Michael Winikoff provided the schematic depictions of the various processes and figures considered in this work. With approval from the University of Minnesota and the MN Corn Growers Association (our funding organizations), intellectual property rights have been waived, and HydroChar LLC has submitted a provisional patent application, later converted into a US patent application related to this technology. No allowance of any claims has been received as of this writing.

\section{Supporting Information}

Additional supporting information may be found in the online version of this article at the publisher's web-site. 


\begin{tabular}{|l|l|}
\hline Filename & Description \\
\hline bit24924-sm-0001-SupData.docx741.1 KB & Supplementary Information \\
\hline
\end{tabular}

Please note: The publisher is not responsible for the content or functionality of any supporting information supplied by the authors. Any queries (other than missing content) should be directed to the corresponding author for the article.

\section{References}

Aden A, 2007. Water usage for current and future ethanol production. Southwest Hydrology, (October), 22-23. Retrieved from http://scholar.google.com/scholar?hl=en\&btnG=Search\&q=intitle:Water+Usage+for+Current+and + Future+Ethanol+Production\#0.

Agler MT, Garcia, ML, Lee ES, Schlicher M, Angenent LT. 2008. Thermophilic anaerobic digestion to increase the net energy balance of corn grain ethanol. Environ Sci Technol 42(17): 6723- 6729.

Alkan-Ozkaynak A, Karthikeyan KG. 2011. Anaerobic digestion of thin stillage for energy recovery and water reuse in corn-ethanol plants. Biores Technol 102(21): 9891- 9896.

Andalib M, Hafez H, Elbeshbishy E, Nakhla G, Zhu J. 2012. Treatment of thin stillage in a high-rate anaerobic fluidized bed bioreactor (AFBR). Biores Technol 121: 411- 418.

Angelidaki I, Alves M, Bolzonella D, Borzacconi L, Campos JL, Guwy AJ, Kalyuzhnyi S, Jenicek P, van Lier JB. 2009. Defining the biomethane potential (BMP) of solid organic wastes and energy crops: A proposed protocol for batch assays. Water Sci Technol 59(5): 927-934.

Bougrier C, Delgenès JP, Carrère H. 2008. Effects of thermal treatments on five different waste activated sludge samples solubilisation, physical properties and anaerobic digestion. Chem Eng J 139(2): 236- 244.

Chen Z, Ma L, Li S, Geng J, Song Q, Liu J, Wang C, Wang H, Li J, Qin Z, Li S. 2011. Simple approach to carboxyl-rich materials through low-temperature heat treatment of hydrothermal carbon in air. App/ Surf Sci 257: 8686- 8691.

Dahlen RBA, Baidoo SK, Shurson GC, Anderson JE, Dahlen CR, Johnston L. 2011. Assessment of energy content of low-solubles corn distillers dried grains and effects on growth performance, carcass characteristics, and pork fat quality in growing-finishing pigs. J Anim Sci 89: 3140-3152.

Falco C, Sieben JM, Brun N, Sevilla M, van der Mauelen T, Morallon E, Cazorla-Amoros D, Titirici M. 2013. Hydrothermal carbons from hemicellulose-derived aqueous hydrolysis products as electrode materials for supercapacitors. ChemSusChem 6: 1- 10.

Heilmann SM, Davis HT, Jader LR, Lefebvre PA, Sadowsky MJ, Schendel FJ, von Keitz MG, Valentas KJ. 2010. Hydrothermal carbonization of microalgae. Biomass Bioenergy 34: 375- 882.

Heilmann SM, Jader LR, Sadowsky MJ, Schendel FJ, von Keitz MG, Valentas KJ. 2011a. Hydrothermal carbonization of distiller's grains. Biomass Bioenergy 35: 2526- 2533.

Heilmann SM, Jader LR, Harned LA, Sadowsky MJ, Schendel FJ, Lefebvre PA, von Keitz MG, Valentas KJ. 2011b. Hydrothermal carbonization of microalgae II. Fatty acid, char and algal nutrient products. Appl Energ 88: 3286- 3290.

House SD, Larson PA, Johnson RR, DeVries JW, Martin DL. 1994. Gas chromatographic determination of total fat extracted from food samples using hydrolysis in the presence of antioxidant. J AOAC Int 77: 960-965.

Jacques K, Lyons TP, Kelsall DR. 1999. The alcohol textbook. 3rd edn. Nottingham UK: Nottingham University Press. p 62.

Jirka AM, Carter MJ. 1975. Micro semiautomated analysis of surface and waste waters for chemical oxygen demand. Anal Chem 47(8): 1397- 1402.

Khanal SK. 2008. Anaerobic biotechnology for bioenergy production. lowa: Wiley-Blackwell. p 179.

Kim Y, Mosier NS, Hendrickson R, Ezeji T, Blaschek H, Dein B, Cotta M, Dale B, Ladisch MR. 2008. Composition of corn dry-grind ethanol by-products: DDGS, wet cake, and thin stillage. Biores Technol 99: 5165- 5176.

Liska AJ, Yang HS, Bremer VR, Klopfenstein TJ, Walters DT, Erickson GE, Cassman KG. 2009. Improvements in life cycle energy efficiency and greenhouse gas emissions of corn-ethanol. $J$ Ind Ecol 13(1): 58- 74. 
Liu K, Rosentrater KA, 2012. Distillers grains: Production, properties, and utilization. Florida: Taylor and Francis Group. $p 82$.

Meredith J. 2003. Understanding energy use and energy users in contemporary ethanol plants. In: The alcohol textbook. 4th edn. KA Jacques, TP Lyons, DR Kelsall, editors. Nottingham, UK: Nottingham University Press, p 355- 361.

Mumme J, Eckervogt L, Pielert J, Diakite M, Rupp F, Kern J. 2011. Hydrothermal carbonization of anaerobically digested maize sludge. Biores Technol 102: 9255-9260.

Owen WF, Stuckey DC, Healy JB, Young LY, McCarty PL. 1979. Bioassay for monitoring biochemical methane potential and anaerobic toxicity. Water Res 13(6): 485- 492.

Rausch KD, Belyea RL. 2006. The future of coproducts from corn processing. App/ Biochem Biotechnol 128: 47-86.

Schaefer SH, Sung S. 2008. Retooling the ethanol industry: Thermophilic anaerobic digestion of thin stillage for methane production and pollution prevention. Water Environ Res 80(2): 101- 108.

Sevilla M, Falco C, Titirici M, Fuertes AB. 2012. High-performance carbon dioxide sorbents from algae. RSC Adv 2: 12792-12797.

Van Krevelen DW. 1950. Graphical-statistical method for the study of structure and reaction processes of coal. Fuel 29: 269- 284.

Wei L, Sevilla M, Fuertes AB, Mokaya R, Yushin G. 2011. Hydrothermal carbonization of abundant renewable natural organic chemicals for high-performance supercapacitor electrodes. Adv Energ Mater 1(3): 356- 361.

Wilson CA, Novak JT. 2009. Hydrolysis of macromolecular components of primary and secondary wastewater sludge by thermal hydrolytic pretreatment. Water Res 43(18): 4489-4498. 